\title{
Article
}

\section{Recycling of plastic waste by using pyrolysis reactor: A case study of first marine protected area of Pakistan (Astola} Island)

\author{
Misbah Youngish ${ }^{1}$, Uzaira Rafique ${ }^{2}$ and Asma Jabeen ${ }^{2, *}$ Faisal Baloch ${ }^{2, *}$
}

1 Department of Environmental Sciences, Fatima Jinnah Women University, Rawalpindi, Pakistan(dostfjwu@edu.pk)

2 Department of planning, development and special initiatives Islamabad (Environment and climate change section)

* $\quad$ Correspondence: asmajabeen@fjwu.edu.pk;baloch.Faisal78@gmail.com

Abstract: Astola Island is the first marine protected area of Pakistan acknowledged 2017, June 15. It is a rich biodiversity hotspot, Ramsar site inhabiting endangered species like Green turtle, Hawksbill turtle, and Arabian Humpback whale. A saw-scaled Russell's viper is endemic to Island. Marine ecology of Astola Island is affected by plastic pollution resulting in coral destruction, ocean acidification, global warming, fishing nets blockage, water pollution, and coastal erosion. Zeolite catalyst synthesized from environmentally friendly way by coal fly ash to degrade collected plastic waste from Island into useful products in pyrolysis reactor.Three type of organosilane are used for functionalization of synthesized catalyts to increase their silica content for better catalytic activity by using(1)Octyltriethoxysilane(OS),(2)Phenyltriethoxysilane(PS),(3)Vinyltriethoxysilane(VS).Zeolite functionalize with octyltriethoxy silane (ZO) shows the highest performance in plastic pyrolysis, resulting in lower degradation temperature, low residue and more product formation may be due to having long chain hydrocarbon and acidic sites. Plastic recycling is the promising solution to tackle plastic blooming issue. Which is negatively impacting all the compartments of ecosystem especially marine environment.

Keywords: Astola Island; Plastic pollution; Zeolite catalyst; Recycling

\section{Introduction}

In developing countries, plastic pollution is of prime concern that affects all compartments of the environment, especially water. Plastic litter varies in composition and quantity in seawaters, beaches and deep seas [1].The environmental and human impacts of plastic waste are indicative of nonchalant behavior of human towards nature. Pakistan has coastline of $1050 \mathrm{~km}$, out of which 800 $\mathrm{km}$ falling in the Balochistan province and $250 \mathrm{~km}$ in Sindh. Significance of establishing of the marine protected areas (MPA's) in Pakistan at different levels for conservation of ecosystem, cultural value and scientific reference site is contributing to the sustainable tourism, recreational activities and local community's employment [2,3].

Astola Island is the first marine protected area of Pakistan acknowledged on June 15, 2017. This is also known as Jazeera Haft Taller (Island of seven hills). It covers an area of $6.7 \mathrm{~km}^{2}$ in width, 240 feet high above sea level and buffer zone of $401.47 \mathrm{~km}{ }^{2}$. It is a rich biodiversity hotspot, inhabiting endangered species like Green turtle, Hawksbill turtle, and Arabian Humpback whale.A saw-scaled 
Russell's viper is endemic to Island. Marine ecology of Astola Island is affected by plastic pollution resulting in coral destruction, ocean acidification, global warming, fishing nets blockage, water pollution, illegal fishing and coastal erosion. Astola is uninhabited offshore largest island due to high tides and roughness of the[4].

Plastic degradation fragments and filaments enters the food web in the ocean threatening marine species health and major ecological catastrophes that endangers vulnerable species. Plastic have different shape, color and size ingested mistakenly by animals [5] cause serious problem in migration, lower level of reproduction, endocrine abnormalities, internal injuries and even death [6].Sandy beaches is the most accumulated area of plastic litter, plastic destructed not only coastal area but also rises sea level [7].Nesting activities make difficult due to presence of plastic in marine environment[8].Macro plastic converted to unseen form of plastic pollutants which have been detected in 1970's is named as microplastic.Microplastic reported in the sediments of Yangtze Estuary, South China Sea, yellow sea and Bohai Sea [9].Micro plastic are heterogeneous group of materials exhibit distinct physiochemical properties related to sources of emissions. Biological effects of micro plastic influenced by many factors like size, composition and polymeric additives.

The traditional method for plastic degradation was incineration, but not environmentally friendly. Due to carbon dioxide emission released in the air but pyrolysis is the most promising technique for plastic waste management [10].Plastic waste energy is the new paradigm for plastic related problems, so that plastics can be a potential new cheap energy source of important chemicals which are recyclable. Thermal degradation produces low hydrocarbons fuels and other chemicals by inert atmosphere by pyrolysis of plastic waste in the temperature ranging from $500^{\circ} \mathrm{C}$ to $800^{\circ} \mathrm{C}$. This technique leads to a wide product distribution and highly energy efficient.

Catalytic degradation of plastic significantly reduces the temperature required to polymer cracking. Liquids fuels and gas which are highly desired chemical products requires proper selection of the catalytic system [11].There are several catalysts used for plastic degradation. Marine environment threatened by anthropogenic activities, need of hour is to understand concerned people perceptions of plastics and their environmental impacts if we want to reduce the input of plastic into the ocean [12].Zeolites are crystalline micro porous alumina silicate materials which are stable over a wide range of temperature. Zeolite synthesized from both naturally (e.g. Coal fly ash) and synthetically from pure chemicals. The coal fly ash precursor for zeolite synthesis is environmentally friendly and has major components like Alumina (Al) and silica (Si) [13].Zeolites are stable up to $6500^{\circ} \mathrm{C}-1000^{\circ} \mathrm{C}$ mostly containing high silica- to- alumina ratios. It exhibits acidity comparatively higher than previous silica-alumina catalyst. Zeolites have both Bronsted and Lewis acid sites. These acidic sites present on zeolite affected by nature, type, density, strength distribution, location and geometric distribution of acidic sites. Synthesis of zeolite by coal fly ash is environmentally friendly way.Organosilane was used for the surface modification of zeolites [14],[15].Zeolite modifies or grafted with octyltriethoxy silane (OTEOS) by variable amount 
because of maximum active sites accessibilty.It also increases hydrophobicity of zeolites. These modify zeolites have several applications [16].

Pyrolysis is obtained through different catalytic processes like thermal, hydrocarbon and catalytic. Thermal catalysis has a drawback as; it produces more carbon range products. But compared to thermal, catalytic degradation decreased reaction temperature and also increase product yield[17],[18].ZSM-5 zeolite catalyst in the plastic waste pyrolysis plays an important on the color of oil, oil yield and also on capability to decompose the polymer[]19].Pyrolysis with the help of catalyst in the range of temperature of $300^{\circ} \mathrm{C}-650^{\circ} \mathrm{C}$ helps to improve bio-oil hydrocarbon range because of zeolite molecular structure and their strong acid sites[20]. Pyrolysis is convenient technique than gasification and high-pressure liquefaction because economically cheap and the manipulation of parameters during process is easy [21].

Pyrolysis put up to the circular economy, waste plastic converted thermo chemically into degradation products using polyethylene and polypropylene feedstock's [22].Production of biodiesel was achieved by renewable resources. In diesel engines used as additive, replace petrol-diesel, reduce gaseous pollutants, increase economy, waste management of biomass and also this leads to acquiring sustainability [23].Plastic recycling has become very lucrative activity aims to achieved sustainable development through providing benefits to the current and future generations, economic prosperity and social equity [24].

\section{Results}

\subsection{Formatting of Mathematical Components}

Rate of conversion $(\mathbf{\%})=\underline{\text { Initial mass of plastic }- \text { Mass of plastic left in the reactor }} \times 100$

Initial mass of plastic.

$$
\begin{aligned}
\text { Yield of oil }= & \underline{\text { Mass of the obtained oil }} \times 100 \\
& \text { Initial weight of plastic waste sample }
\end{aligned}
$$

Oil recovery $=\underline{\text { Volume of oil recovered }(\mathrm{ml})} \times 100$ 


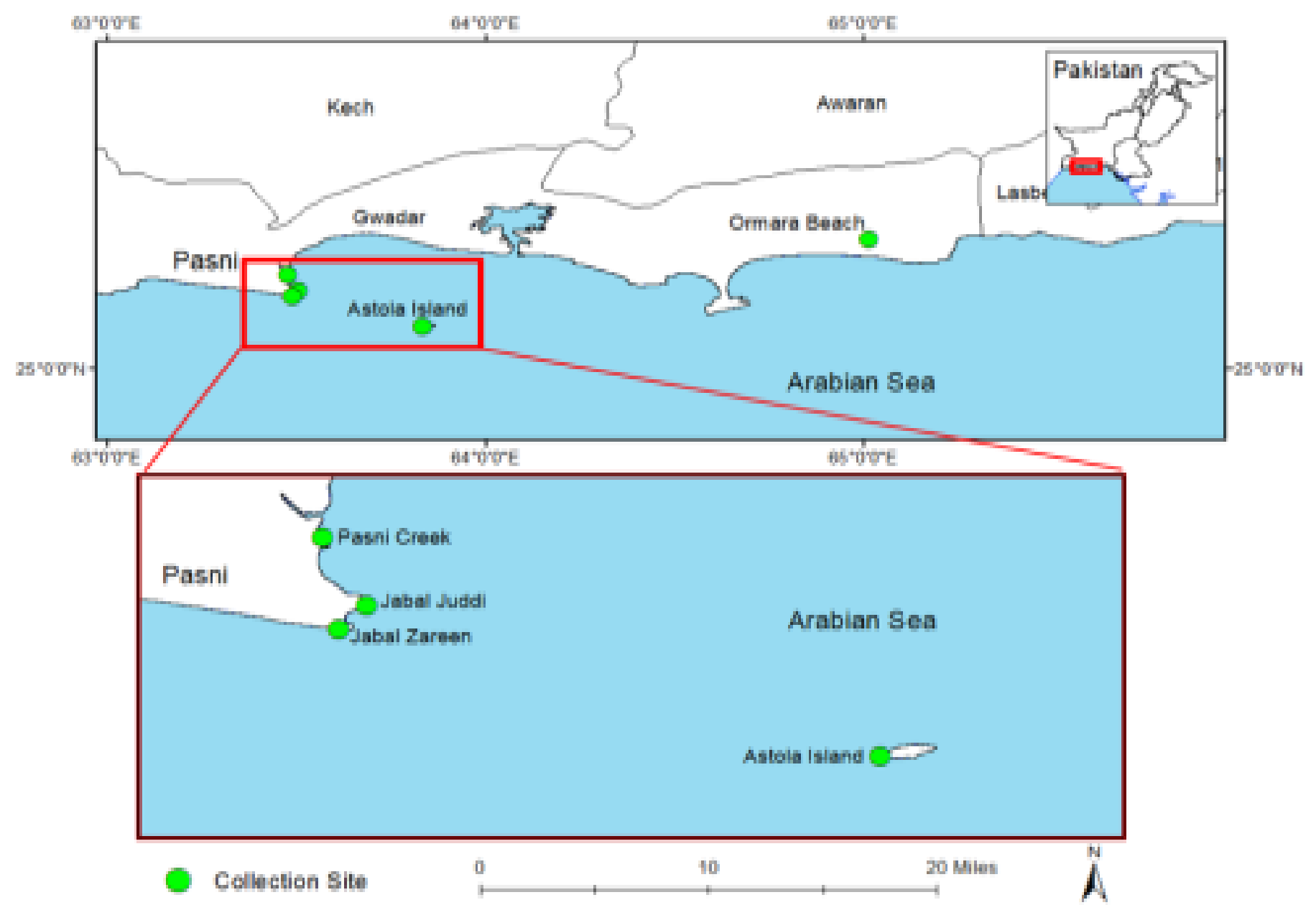

Figure 1.Showing map of collection points of sediments and water samples. The geographical coordinates of sampling site was recorded through global positioning system (GPS). The areas were chosen due to accumulation of plastic waste and garbage.

\begin{tabular}{|l|l|l|l|l|l|l|l|}
\hline Sample Code & $\mathrm{Al}$ & $\mathrm{Si}$ & $\mathrm{Ca}$ & $\mathrm{O}$ & $\mathrm{Na}$ & $\mathrm{K}$ & $\mathrm{C}$ \\
\hline $\mathrm{Z}$ & 16.49 & 23.55 & 33.99 & 35.48 & 7.14 & 10.03 & 6.52 \\
\hline $\mathrm{ZP}$ & 11.10 & 47.29 & 21.39 & 33.94 & 3.25 & 1.79 & 6.86 \\
\hline $\mathrm{ZV}$ & 20.87 & 23.83 & 43.87 & 31.53 & 9.06 & 27.48 & 12.69 \\
\hline
\end{tabular}


Table No. (2) FTIR assignment of pyrolysis oil

\begin{tabular}{|l|l|l|}
\hline Wave number(cm-1) & Type of vibration & Name of functional group \\
\hline $3626.29-35.832$ & O-H strong broad & Alcohol,Amide,phenol, \\
\hline $2351.30-20.98$ & Aliphatic C-H stretching & Alkane \\
\hline 1651.12 & C=C stretching & Alkene/phenylring substitution overtone \\
\hline 1415.80 & C-H bending & Alkane \\
\hline $1392.65-1325.14$ & C-H scissorimg and bending & Aromatic Amines \\
\hline $1290.42-1240.27$ & C-N stretch & Aliphatic amines \\
\hline 1016.52 & C-N stretch & Alchol,carboxylic acid,ester \\
\hline 1178.65 & C-O stretching & Alkane \\
\hline 707.90 & C-H rock & \\
\hline
\end{tabular}

C-H group stretch around(3000-2800 $\left.\mathrm{cm}^{-1}\right)$ were more intense bands and angular deformation occued at $(1464 \mathrm{~cm}-1-1379 \mathrm{~cm}-$

$\left.{ }^{1}\right)$.Carbonyl absorption band (1750 -1735 $\left.\mathrm{cm}^{-1}\right)$ and aliphatic ester absorption band (1300-100 $\left.\mathrm{cm}^{-1}\right)$ shows the presence of biodisel in the samples.Low intensity bands $\left(675-900 \mathrm{~cm}^{-1}\right)$ are aromatic compounds [30].

Table No (3). Viscosity of oil at two different temperatures

\begin{tabular}{|l|l|l|l|}
\hline Serial number & Fuel type & Viscosity at $60^{\circ} \mathrm{C}(\operatorname{cost})$ & Viscosity at $100^{\circ} \mathrm{C}(\cos )$ \\
\hline 1 & Feedstock+catalyts & 2.2 & 2.1 \\
\hline
\end{tabular}

Fuel densities are much similar due to the same nature of feedstock consists of Polyethylene both low and high density, polypropylene and polyethylene terephthalate. 
In figure (a) and table (b) shows the degradation of plastic waste using pyrolysis reactor. All catalysts decreased the initial degradation temperature which is more expressive for the catalyst $\mathrm{ZO}$ that is $180^{\circ} \mathrm{C}$ and total reaction time was 63 minutes. The more product formation with ZP catalyst that was $80 \mathrm{ml}$ (oil).Pyrolysis is a circular economy change waste product into original form where it performs same function again or new function without end of life cycle of plastics

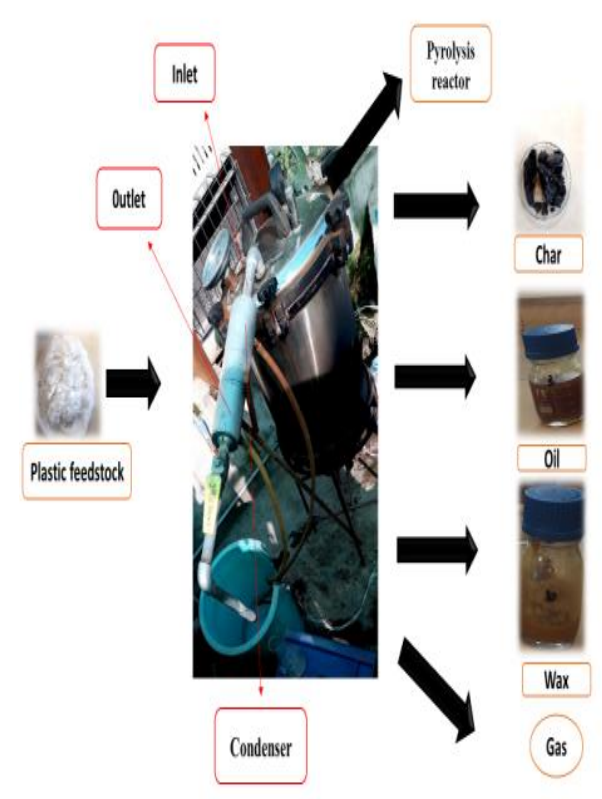

(a) 


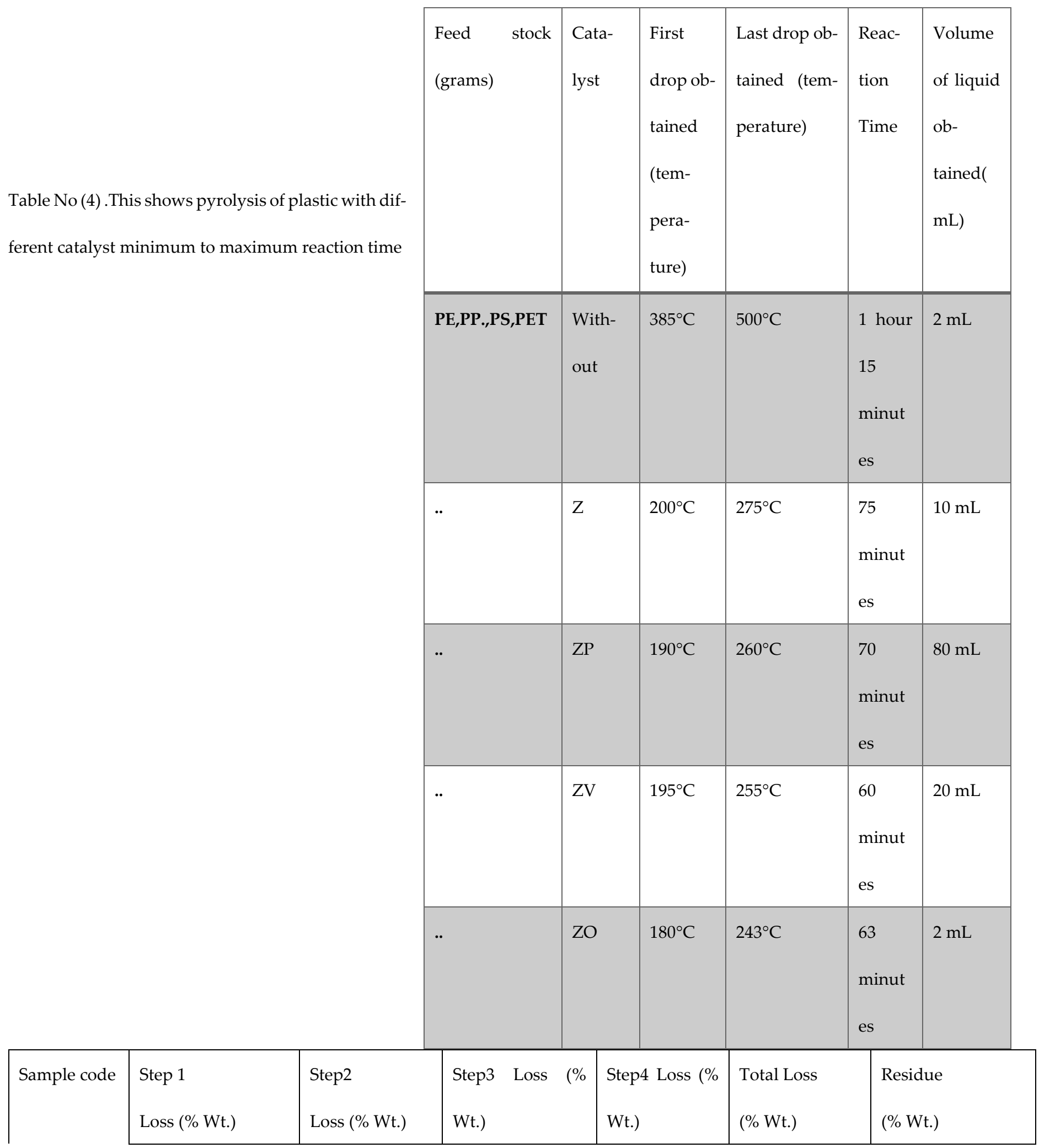




\begin{tabular}{|c|c|c|c|c|c|c|}
\hline Z & $\begin{array}{l}83.93 \\
0-142.2^{\circ} \mathrm{C}\end{array}$ & $\begin{array}{l}74.48 \\
335.4^{\mathrm{c}} \mathrm{O} .\end{array}$ & $\begin{array}{l}34.90 \\
488.8^{\circ} \mathrm{C}\end{array}$ & $\begin{array}{l}29.52 \\
799.1^{\circ} \mathrm{C}\end{array}$ & 29.37 & 70.63 \\
\hline $\mathrm{ZP}$ & $\begin{array}{l}88.44 \\
0-153.4^{\mathrm{c}} \mathrm{O} .\end{array}$ & $\begin{array}{l}82.73 \\
337.9^{\mathrm{c}} \mathrm{O} .\end{array}$ & $\begin{array}{l}65.18 \\
452.7^{\mathrm{c}} \mathrm{O} .\end{array}$ & $\begin{array}{l}74.56 \\
584.6^{\mathrm{c}} \mathrm{O} .\end{array}$ & 41.15 & 58.85 \\
\hline ZV & $\begin{array}{l}9.77 \\
0-184.2^{\mathrm{c}} \mathrm{O} .\end{array}$ & $\begin{array}{l}89.87 \\
330.1^{\mathrm{c}} \mathrm{O} .\end{array}$ & $\begin{array}{l}46.86 \\
477.0^{\mathrm{c}} \mathrm{O} .\end{array}$ & $\begin{array}{l}43.64-52.08 \\
626.9-702.8^{\mathrm{c}} \mathrm{O} .\end{array}$ & 41.12 & 58.88 \\
\hline $\mathrm{ZO}$ & $\begin{array}{l}85.58 \\
0-133.6^{\mathrm{c}} \mathrm{O} .\end{array}$ & $\begin{array}{l}77.42 \\
326.2^{\mathrm{c}} \mathrm{O} .\end{array}$ & $\begin{array}{l}58.59 \\
478.7^{\mathrm{c}} \mathrm{O} .\end{array}$ & $\begin{array}{l}41.64-52.08 \\
626.9^{\mathrm{c}} \mathrm{O} .\end{array}$ & 59.1 & 40.9 \\
\hline
\end{tabular}

Zeolite without functionalization exhibited a lower degradation rate compared to others, so ZO showed higher catalytic activity may be associated with the greater number of strong acidic sites.

\subsection{Discussion}

3.1Fourier transformation infrared spectroscopy (FTIR):

\subsubsection{FTIR of Zeolite catalyst:}

Functional group zeolites were determined by FTIR analysis [25].FTIR of the zeolite was done in the laboratory using KBr pellets at room temperature after background correction. The FTIR spectra of zeolite catalyst are in the range of 4,000 to $400 \mathrm{~cm}^{-1}$.FTIR analysis of zeolites shows absorption band in the $3424 \mathrm{~cm}^{-1}$ region which attributed (Si-OH) terminal silanol group[26].Asymmetric stretch of Si-0 vibration occurred at $1049 \mathrm{~cm}$ or $800 \mathrm{~cm}^{-1}$.the band near $470 \mathrm{~cm}^{-1}$ shows bending mode of Si-O-Si [27].

\subsubsection{FTIR of oil obtained from plastic waste:}

Functional group of each collected fuel was determined by FTIR analysis. Sodium chloride cells were used to perform the analy sis[28] and sample were diluted in methanol. After distillation this fuel is used as alternative of diesel [29].

3.2. Energy dispersive $x$-ray $(E d x)$ analysis: 
Four zeolite catalyst concentrations were measured by suggests that of energy dispersive x-ray analysis ( $\mathrm{Si}, \mathrm{Al}, \mathrm{O}, \mathrm{CA}, \mathrm{K}, \mathrm{C}, \mathrm{Na})$, the $\mathrm{Si} / \mathrm{Al}$ ratios within the vary of $47(\mathrm{Si}) / 10(\mathrm{Al})$. This results showed that very same weight percentage share as antecedently studied $\mathrm{Si} / \mathrm{Al}$ quantitative relation $46 \mathrm{Si} / 10 \mathrm{Al}[31]$.

3.3. Degradation of plastic waste by using pyrolysis reactor:

Pyrolysis reactor setup according to method proposed [32].All catalysts decreased the initial degradation temperature which is more expressive for the catalyst $\mathrm{ZO}$ that is $180^{\circ} \mathrm{C}$ and total reaction time was 63 minutes. The more product formation with $\mathrm{ZP}$ catalyst that was $80 \mathrm{ml}$ (oil).It was found that chemical action on plastic waste within the temperature varies $175^{\circ} \mathrm{C}-500^{\circ} \mathrm{C}$ depending on

- Temperature,

- Quantity of catalyst

- $\quad$ Reaction time.

Because of chemical action degradation of plastic waste upon heating, to get $5 \mathrm{~kg}$ wax, $10 \mathrm{~kg}$ charcoal, $5 \mathrm{~kg}$ of gas and maximum 80 $\mathrm{ml}$ liquid product.

3.4.Analysis of pyrolysis fuel:

Two type of analysis generally one is physical and other is chemical analysis.

3.5. Physical analysis of pyrolysis oil:

- Color of the oil

- Viscosity of oil

- Calorific value of oil

3.5.1. Yield of oil:

3.5.2. Color of the fuel:

The colors were identified visually, light yellow to orange in color due to different polymer composition.

3.5.3. Viscosity of oil:

Viscosity of oil produced from plastic was measured by using Ostwald Viscometer. The viscometer was filled with the oil up to mark .after the suction was done to pull it to the upper reserivor.The suction was removed and the oil was allowed to go back to the lower reservoir. During this movement from upper to lower mark on each reservoir, the time was measured using stopwatch. Water was used as a reference material for the viscometer as its density is well- known and calculated relative viscosity of the oil by using Oswald equation.

3.5.4. Calorific value of fuel: 
Calorific value is the heat energy produced by the oil upon combustion under constant conditions. The calorific value was used by bomb calorimeter in National Cleaner Production Center (NCPC) Morgah, Rawalpindi. The test method used for determining the calorific value was ASTM D4858. The calorific value of oil was $45.9 \mathrm{MJ} / \mathrm{Kg}$ was determined.

\subsection{Thermo gravimetric analysis (TGA):}

Thermal Decomposition Analysis about half dozen mg of HDPE and PP was heated by a non-isothermal temperature program, from $30^{\circ} \mathrm{C}$ temperature to $800{ }^{\circ} \mathrm{C}$ at twenty ${ }^{\circ} \mathrm{C} / \mathrm{min}$ of heating rate underneath sixty $\mathrm{mL} / \mathrm{min}$ of atomic number 7 atmosphere, using a TGA (Pyris Diamond, Perkin-Elmer, Waltham, MA, USA).For the chemical change TG analysis, 6 mg of catalyst was mixed with plastics and the same temperature program was applied. TGA studies showed that without catalyst more residues left but with the addition of zeolite catalyst having different organo silane modifications are fewer residues and more product formation.

\section{Materials and Methods}

The study area was visualized through ArcGIS (10.7.1) to select the sampling sites. Sampling was carried out in March, 2020 and weather conditions were mostly sunny Samples were collected on five different beaches including Ormara, Jabbal Juddi, Jabbal zareen, Pasni creek beach and Astola Island (first marine protected area).

Coal fly ash was provided by National Cleaner Production (NCPC) Rawalpindi Pakistan, Sodium Meta silicate (BDHL), Aluminum isoprop-oxide (Sigma Aldrich), tri ethoxy octyl silane, phenyl tri ethoxy silane, trimethoxy vinyl silane, potassium hydroxide, sodium hydroxide purchased from Merck. All the chemicals were of analytical grade and used without further purification. Representative plastic samples were prepared by cuttings of plastic $2 \mathrm{~cm}^{2}$ of area.

4.1. Synthesis of zeolite using hydrothermal method

Zeolite is synthesized sodium Meta silicate by using hydrothermal method reported by [33].For this purposes, $8.9 \mathrm{~g}$ of sodium Meta silicate was mixed with $2 \mathrm{~g} \mathrm{NaOH}$ anhydrous form and grounded into fine powder mixture using a pestle and mortar. The dried mixture was transferred into a crucible and placed in a furnace at $500^{\circ} \mathrm{C}$ for 2 hours. The resultant solid mixture and grounded again into fine powder and mixed with $100 \mathrm{ml}$ of deionized water and small quantity of aluminum isopropoxide added and stirred at 600 rpm. The suspended slurry mixture was then placed for autoclave (120 $\mathrm{mmHg} ; 2$ hours). The solid was filtered and washed until $\mathrm{pH}$ 8 was attained. Then, dried in oven at $100^{\circ} \mathrm{C}$ for 12 hours.

\subsection{Functionalization with organosilane}

Organosilane was used for the surface modification of zeolites [34].Functionalization with silane derivatives containing octal group was carried out by refluxing a mixture of zeolite $2 \mathrm{~g}$ and trimethoxyoctylsiane $(2 \mathrm{ml})$ in toluene (70 $\mathrm{mL})$ for $5 \mathrm{hours}$. After Centrifugation the solid was washed with toluene. Silane containing- phenyl group was carried out by refluxing a mixture zeolite (2 
g) and tri ethoxy phenyl silane $(2 \mathrm{ml})$ in toluene $(70 \mathrm{~mL})$ for 5 hours followed by centrifugation and washing of zeolite powder with toluene. Zeolite $2 \mathrm{~g}$ was immersed in toluene $(70 \mathrm{~mL})$ containing tri ethoxy vinyl silane $(2 \mathrm{ml})$. Then five minutes suspension was shaken at room temperature. The solid was collected by centrifugation and finally dried at $90^{\circ} \mathrm{C}$ for 5 hours. (Hassan et al., 2013).Synthesized zeolites were codes as Z (Without silane), ZP (zeolite modify with phenyl silane), ZV (zeolite modify with vinyl silane), and ZO(zeolite modify with Octyl silane).

\subsection{Conclusions}

The synthesized catalyst ZO showed the highest performance in plastic pyrolysis, resulting in lower degradation temperature, low residue and more product formation might be due to having long chain hydrocarbon and acidic sites. This is the first study to focus on plastic pollution in Astola Island. Recycling of plastic is the most promising solution to conserve biodiversity of all ecosystems especially marine environment. This research recommends proper waste management plan implementation in Astola Island because there is no management plan yet.

Author Contributions: For research articles with several authors, a short paragraph specifying their individual contributions must be provided. The following statements should be used “Conceptualization, X.X. and Y.Y.; methodology, Uzaira Rafique.; software, Faisal Ali Baloch.; validation, Uzaira Rafique, Asma Jabeen. And Faisal Ali Baloch.; formal analysis, Uzaira Rafique.; investigation, Uzaira Rafique.; resources,Faisal Ali Baloch.; data curation, Faisal Ali Baloch.; writing - original draft preparation, Misbah Youngish; writing - review and editing, Misbah Youngish.; visualization, Misbah Youngish.; supervision, Uzaira Rafique and Asma Jabeen.; project administration, Faisal Ali Baloch.. All authors have read and agreed to the published version of the manuscript."

Funding: Please add: “This research received no external funding”

Conflicts of Interest: Declare conflicts of interest or state "The authors declare no conflict of interest."

\section{References}

[1]Kalogerakis, N., Karkanorachaki, K., Kalogerakis, G., Triantafyllidi, E. I., Gotsis, A. D., Partsinevelos, P., \& Fava, F. (2017). Microplastics generation: onset of fragmentation of polyethylene films in marine environment mesocosms. Frontiers in Marine Science, 4, 84.

[2] Siddiqui, P. J., Farooq, S., Shafique, S., \& Farooqi, Z. (2008). Conservation and management of biodiversity in Pakistan through the establishment of marine protected areas. Ocean $\mathcal{E}$ coastal management, 51(5), 377-382.

[3] Waqas, U., Hasnain, S. A., Ahmad, E., Abbasi, M., \& Pandrani, A. (2011). Conservation of green turtle (Chelonia mydas) at Daran beach, Jiwani, Balochistan. Pakistan Journal of Zoology, 43(1).

[4]Pakistan, M. F. F. (2018). Astola Island-First Marine Protected Area in Pakistan.

[5]Isangedighi, I. A., David, G. S., \& Obot, O. I. (2018). Plastic waste in the aquatic environment: impacts and management. Environment, 2, 1-31. 
[6] Chae, Y., \& An, Y. J. (2018). Current research trends on plastic pollution and ecological impacts on the soil ecosystem: A review. Environmental pollution, 240, 387-395.

[7] Fuentes, E., Coe, H., Green, D., De Leeuw, G., \& McFiggans, G. (2010). On the impacts of phytoplankton-derived organic matter on the properties of the primary marine aerosol-Part 1: Source fluxes. Atmospheric Chemistry E Physics Discussions, 10(6).

[8] Gündoğdu, S., Yeşilyurt, İ. N., \& Eras, C. (2019). Potential interaction between plastic litter and green turtle Chelonian Midas during nesting in an extremely polluted beach. Marine pollution bulletin, 140, 138-145.

[9] Zhang, J., Chen, M., Huang, J., Guo, X., Zhang, Y., Liu, D., ... \& Wang, J. (2019). Diversity of the microbial community and cultivable protease-producing bacteria in the sediments of the Bohai Sea, Yellow Sea and South China Sea. Plos one, 14(4), e0215328. [10] Constantinescu, R. R., Zainescu, G. A., Crudu, M., \& Bostaca, G. (2019). Retanning Bioagent Used in Leather Processing and Process of Obtaining Thereof. REVISTA DE CHIMIE, 70(11), 3878-3880.

[11] Covarrubias, C., Gracia, F., \& Palza, H. (2010). Catalytic degradation of polyethylene using nanosized ZSM-2 zeolite. Applied Catalysis A: General, 384(1-2), 186-191.

[12] Henderson, L., \& Green, C. (2020). Making sense of microplastics? Public understandings of plastic pollution. Marine Pollution Bulletin, 152, 110908.

[13] He, X., Yao, B., Xia, Y., Huang, H., Gan, Y., \& Zhang, W. (2020). Coal fly ash derived zeolite for highly efficient removal of Ni2+ inwaste water. Powder Technology, 367, 40-46.

[14] Pang, H., Yang, G., Li, L., \& Yu, J. (2020). Efficient transesterification over two-dimensional zeolites for sustainable biodiesel production. Green Energy \& Environment.

[15] Li, J., Li, M., Song, Q., Wang, S., Cui, X., Liu, F., \& Liu, X. (2020). Efficient recovery of Cu (II) by LTA-zeolites with hierarchical pores and their resource utilization in electrochemical denitrification: Environmentally friendly design and reutilization of waste in water. Journal of Hazardous Materials, 122554.

[16] Novak, S., Chaves, T. F., Martins, L., \& Santilli, C. V. (2020). Preparation of hydrophobic MFI zeolites containing hierarchical micro-mesopores using seeds functionalized with octyltriethoxysilane. Colloids and Surfaces A: Physicochemical and Engineering Aspects, 585, 124109.

[17] Xu, Z., Xu, X., Zhang, Y., Yu, Y., \& Cao, X. (2020). Pyrolysis-temperature depended electron donating and mediating mechanisms of biochar for Cr (VI) reduction. Journal of hazardous materials, 388, 121794.

[18] Qin, L., Wu, Y., Hou, Z., \& Jiang, E. (2020). Influence of biomass components, temperature and pressure on the pyrolysis behavior and biochar properties of pine nut shells. Bioresource Technology, 313, 123682. 
[19] Kulkarni, S. V., \& Shastri, Y. (2020). Economic Analysis and Life Cycle Assessment of Pyrolysis of Plastic Waste in Mumbai, India. In Sustainable Waste Management: Policies and Case Studies (pp. 453-463). Springer, Singapore.

[20] Mukherjee, A., Ruj, B., Gupta, P., \& Sadhukhan, A. K. (2020). A Study on Pyrolysis of Plastic Wastes for Product Recovery and Analysis. In Urban Mining and Sustainable Waste Management (pp. 329-339). Springer, Singapore.

[21] Sharuddin, S. D. A., Abnisa, F., Daud, W. M. A. W., \& Aroua, M. K. (2017). Energy recovery from pyrolysis of plastic waste: Study on non-recycled plastics (NRP) data as the real measure of plastic waste. Energy Conversion and Management, 148, 925-934.

[22] Sharuddin, S. D. A., Abnisa, F., Daud, W. M. A. W., \& Aroua, M. K. (2016). A review on pyrolysis of plastic wastes. Energy conversion and management, 115, 308-326.

[23] Paradela, F., Pinto, F., Gulyurtlu, I., Cabrita, I., \& Lapa, N. (2009). Study of the co-pyrolysis of biomass and plastic wastes. Clean Technologies and Environmental Policy, 11(1), 115-122.

[24] Karaduman, A. (2002). Pyrolysis of polystyrene plastic wastes with some organic compounds for enhancing styrene yield. Energy sources, 24(7), 667-674.

[25] Mittal, H., Al Alili, A., \& Alhassan, S. M. (2020). High efficiency removal of methylene blue dye using $\kappa$-carrageenan-poly (acrylamide-co-methacrylic acid)/AQSOA-Z05 zeolite hydrogel composites. Cellulose, 27(14), 8269-8285.

[26] Abdullah, A. H., Mat, R., Somderam, S., Abd Aziz, A. S., \& Mohamed, A. (2018). Hydrogen sulfide adsorption by zinc oxideimpregnated zeolite (synthesized from Malaysian kaolin) for biogas desulfurization. Journal of industrial and engineering chemistry, 65, 334-342.

[27] Al-Dughaither, A. S., \& de Lasa, H. (2014). HZSM-5 zeolites with different SiO2/Al2O3 ratios. Characterization and NH3 desorption kinetics. Industrial E Engineering Chemistry Research, 53(40), 15303-15316.

[28] Cafiero, L., Fabbri, D., Trinca, E., Tuffi, R., \& Ciprioti, S. V. (2015). Thermal and spectroscopic (TG/DSC-FTIR) characterization of mixed plastics for materials and energy recovery under pyrolytic conditions. Journal of Thermal analysis and Calorimetry, 121(3), 1111-1119.

[29] Singh, S., Wu, C., \& Williams, P. T. (2012). Pyrolysis of waste materials using TGA-MS and TGA-FTIR as complementary characterisation techniques. Journal of Analytical and Applied Pyrolysis, 94, 99-107.

[30] Kumar, S., \& Singh, R. K. (2011). Recovery of hydrocarbon liquid from waste high density polyethylene by thermal pyrolysis. Brazilian journal of chemical engineering, 28(4), 659-667.

[31 ]Wang, C., Shi, H., \& Li, Y. (2011). Synthesis and characteristics of natural zeolite supported Fe3+-TiO2 photocatalysts. Applied surface science, 257(15), 6873-6877.

[32] Wu, A. C., \& Chen, S. C. (1995). U.S. Patent No. 5,411,714. Washington, DC: U.S. Patent and Trademark Office. 
[33] Chen, H., Wydra, J., Zhang, X., Lee, P. S., Wang, Z., Fan, W., \& Tsapatsis, M. (2011). Hydrothermal synthesis of zeolites with three-dimensionally ordered mesoporous-imprinted structure. Journal of the American Chemical Society, 133(32), $12390-12393$.

[34] Bonaccorsi, L., Bruzzaniti, P., Calabrese, L., \& Proverbio, E. (2016). Organosilanes functionalization of alumino-silica zeolites for water adsorption applications. Microporous and Mesoporous Materials, 234, 113-119. 